\title{
Implementation of Zigbee Technology for Patient HealthCare Monitoring System
}

\author{
Shivachandra Hindinamani ${ }^{1}$, Anant Baliwant Bodas ${ }^{2}$ \\ Assistant Professor, Department of Electrical Engineering, Yashoda Technical Campus, Satara, India ${ }^{1,2}$
}

\begin{abstract}
This paper deals with development of microcontroller based health monitoring system for heartbeat, temperature and oxygen using Zigbee. Now a days, nation population increases demands for caretaking because of these reason monitoring system are the most important system. In this paper we use wireless sensor network based on Zigbee technology. This monitoring system consists of Zigbee based network, microcontroller and three types of sensors which are heartbeat sensor, temperature sensor, oxygen sensor. These sensors are connected to the patient and the output is directly displayed on LCD through Zigbee. The output from the sensor is analog values it is converted to digital and processed by using microcontroller and it will be respond in LCD or computer display.
\end{abstract}

Keywords: Heartbeat sensor, Microcontroller, Oxygen sensor, Temperature sensor, Zigbee network.

\section{INTROUDUCTION}

Now a day, patient health care monitoring system is 3.1. Microcontroller (Arm 7)

important topic and research field. These health ARM7 has a 32 bit data bus and a 32 bit address bus. The monitoring system are developed for many application data types the processor supports are Bytes ( 8 bits) and such as military, homecare unit and hospitals. This paper Words (32 bits), where words must be aligned to four byte describes the Zigbee based health monitoring system. This boundaries. Instructions are exactly oneword, and data system consists of microcontroller, Zigbee technology, operations (e.g. ADD) are only performed on word heartbeat sensor, temperature sensor and oxygen sensor. quantities. Load and store operationscan transfer either The Zigbee is low cost technology. It's rang is $30 \mathrm{~m}$ to 1 bytes or words

$\mathrm{km}$.The technology is intended to be simpler and less expensive than other WPAN's such as Bluetooth. Due to tiny size and low power consumption of microcontroller are applicable where miniaturization is key requirement such as access control and point of sale. This paper describes wireless sensor network on Zigbee technology. It is used for collecting and transferring various monitoring information about patient in hospital. The application consists of Zigbee based network, three sensor i.e. heartbeat sensor, temperature sensor, oxygen sensor.

\section{BLOCK DIAGRAM}

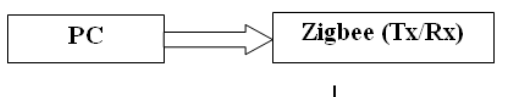

।

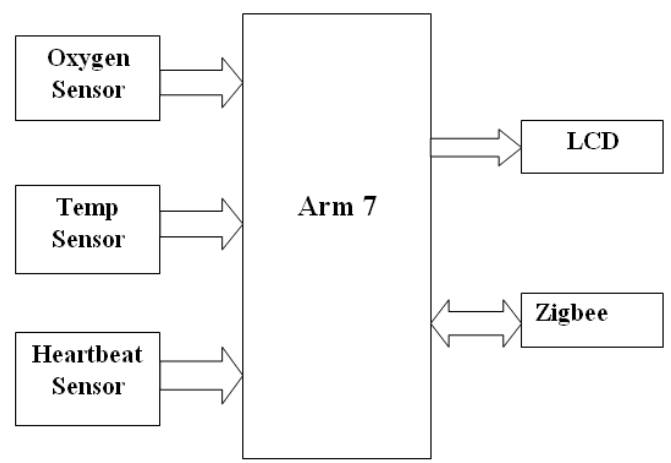

Fig.2.1 Block Diagram of Zigbee
ARM7 supports six modes of operation:

(1) User mode: the normal program execution state

(2) FIQ mode: designed to support a data transfer or channel process

(3) IRQ mode: used for general purpose interrupt handling

(4) Supervisor mode: a protected mode for the operating system

(5) Abort mode: entered after a data or instruction prefetch abort

(6) Undefined mode: entered when an undefined instruction is executed

\subsection{Zigbee}

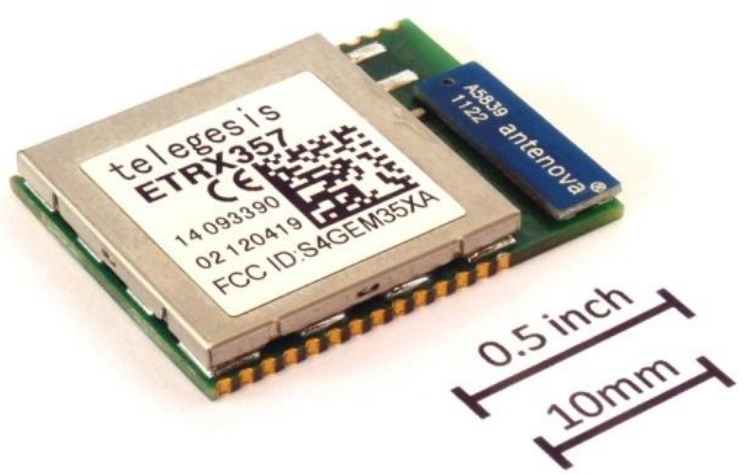

Fig.3.1.Zigbee Module 
Zigbee is low-cost and low-powered mesh network widely deployed for controlling and monitoring applications where it covers 10-100 meters within the range. This communication system is less expensive and simpler than the other proprietary short-range wireless sensor networks as Bluetooth and Wi-Fi.

Zigbee supports different network configurations for master to master or master to slave communications. And also, it can be operated in different modes as a result the battery power is conserved. Zigbee networks are extendable with the use of routers and allow many nodes to interconnect with each other for building a wider area network.

\subsection{Oxygen Sensor}

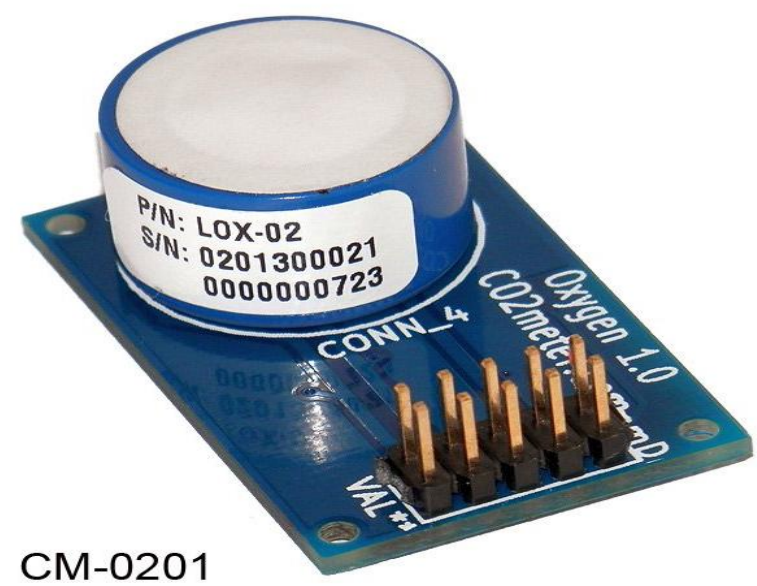

Fig.3.2.Oxygen Sensor

The $\mathrm{O} 2$ sensor is mounted in the exhaust manifold to monitor how much unburnedoxygen is in the exhaust as the exhaust exits the engine. Monitoring oxygen levels in the exhaust is a way of gauging the fuel mixture. It tells the computer if the fuel mixture is burning rich (less oxygen) or lean (more oxygen). An oxygen sensor (or lambda sensor) is an electronic device that measures the proportion of oxygen $\left(\mathrm{O}_{2}\right)$ in the gas or liquid being.

\subsection{Temperature Sensor}

The LM35 is an integrated circuit sensor that can be used to measure temperature with an electrical output proportional to the temperature (in ${ }^{\circ} \mathrm{C}$ ). It can measure temperature more accurately than a using a thermistor. The sensor circuitry is sealed and not subject to oxidation. The LM35 generates a higher output voltage than thermocouples and may not require that the output voltage be amplified. The LM35 has an output voltage that is proportional to the Celsius temperature. The scale factor is $.01 \mathrm{~V} /{ }^{\circ} \mathrm{C}$.

The LM35 does not require any external calibration or trimming and maintains an accuracy of $+/-0.4^{\circ} \mathrm{C}$ at room temperature and $+/-0.8^{\circ} \mathrm{C}$ over a range of $0^{\circ} \mathrm{C}$ to $+100^{\circ} \mathrm{C}$.

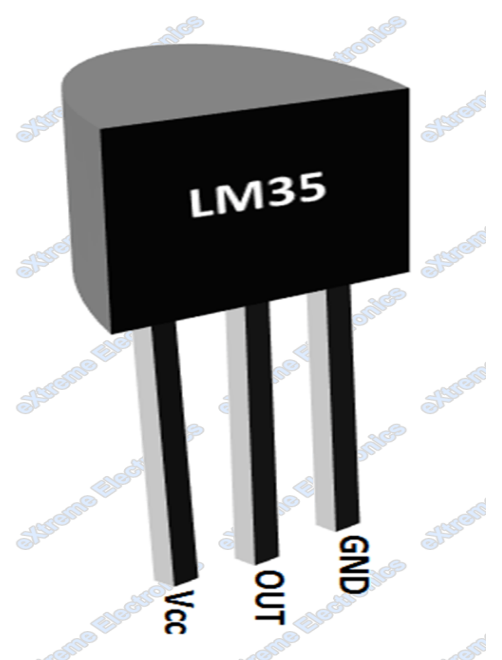

Fig.3.3.Temperature Sensor

Another important characteristic of the LM35 is that it draws only 60 micro amps from its supply and possesses a low self-heating capability.

The LM35 comes in many different packages such as TO92 plastic transistor-like package,T0-46 metal can transistor-like package,8-lead surface mount SO-8 small outline package.

\subsection{Heartbeat Sensor}

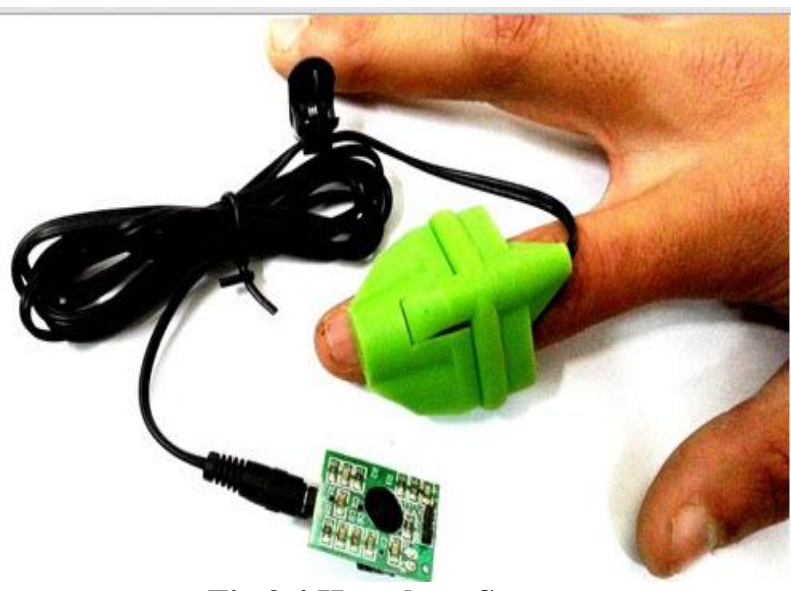

Fig.3.4.Heartbeat Sensor

Heart beat sensor is designed to give digital output of heat beat when a finger is placed on it. When the heart beat detector is working, the beat LED flashes in unison it each heartbeat. This digital output can be connected to microcontroller directly to measure the Beats per Minute (BPM) rate.

It works on the principle of light modulation by blood flow through finger at each pulse. It is applicable for Digital Heart Rate monitor, Patient Monitoring System, Bio-Feedback control of robotics and applications. The heartbeat is indicated by LED. It has instant output digital signal for directly connecting to microcontroller. It has compact size and it's working voltage $+5 \mathrm{~V}$ DC. 


\section{HARDWARE DIAGRAM}

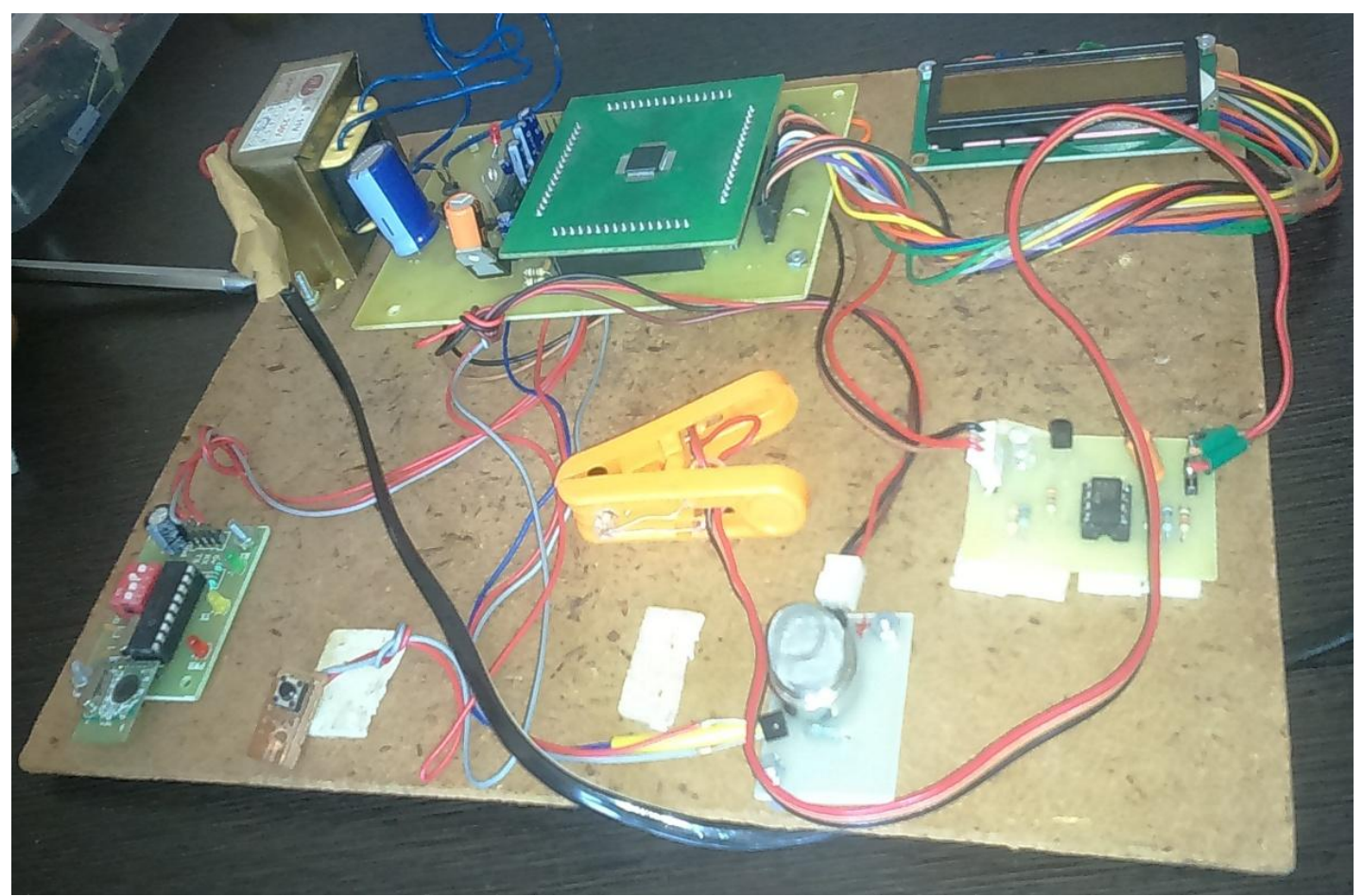

Fig. 4.1 Hardware Prototype Model

\section{CONCLUSION}

We have analyzed wireless health monitoring system of temperature, heartbeat and oxygen of human being using Zigbee based wireless health patient monitoring system. The wireless device is comfortable and reliable for patient as well as medical representative and the speed is high, low power consumption, more highly efficient system.

\section{REFERENCES}

[1] Amruta Nagarkar, M.N. Kakatkar, - Zigbee based wireless patient monitoring.\|l IJSETR, Vol. 2, Issue 2, February 2013.

[2] Malika Charu Rana, -An Indore Wireless Zigbee Based Patient Monitoring System for Hospitals .IJESR, Vol. 04, Issue 02;MarchApril 2013.

[3] Shyr-Kuen Chen, Tsair kao, Chai- Tai Chan, Chih-Ning Huang, Chih-Yen Chiang, Chin-Yu Lai, A Reliable Transmission Protocol for ZigBee Based Wireless Patient Monitoring\| IEEE Trans Inf. Technol. Biomed., Vol.16,No.1 January 2012.

[4] N. V. Panicker, A. Sukesh Kumar "Recent Trends in Wireless Technologies for Healthcare Applications", in Proc. of Int. Conf. on Emerging Trends in Engineering and Technology (ICETET),Munnar, Kerala, India October 4-5, 2013.

[5] Guojin Li, Jing Han, Application of the Medical Care System Based on ZigBee Technology, 2012 IEEE Symposium on Electrical \& Electronics Engineering (EEESYM), pp. 301-303, March 2012.

[6] Mao-Cheng Huang,Jyun-Ciang Huang,Jing-Cyun You, "The Wireless Sensor Network for Home-Care System Using Zigbee", International Conference in Intelligent Information Hiding and Multimedia Signal Processing, pp. 643-646, November 2007.

[7] Istepanian, R.S.H, Jovanov, E., Zhang, Y.T , "Guest Editorial Introduction to the Special Section on M-Health: Beyond Seamless Mobility and Global Wireless Health-Care Connectivity", IEEE Trans. in Information Technology in Biomedicine, Vol.8, No.4,pp.405-414, December 2005.
[8] ZigBee Wireless Sensor Applications for Health, Wellness and Fitness, (2009), Zigbee Alliance.

\section{BIOGRAPHIES}

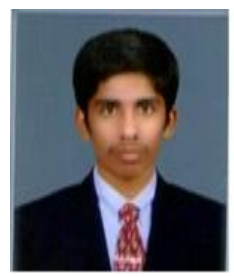

Prof. Shivachandra H. was born in Belagavi district, K.A, India. He received B.E. in Electrical and Electronics Engineering from Basaveshwar Engineering College, Bagalkot (Dist), K.A, India. M. Tech in Energy Systems Engineering from N.M.A.M Institute of Technology, Udupi, K.A, India. He has 5 years of teaching experience in reputed engineering colleges and he is presently working as Asst. Prof \&HOD (EE) Yashoda Technical Campus, Satara(MH) He has various publications in National \& International Journal/Conferences.

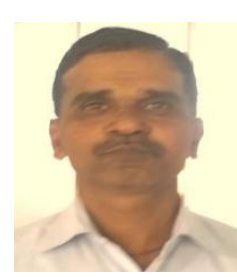

Prof. Anant Bodas. was born in Satara district, M.H, India. He received B.E. in Electrical Engineering from Dnyaneshwar Vidyapith, Pune (Dist), M.H, India. He has 6 years of teaching experience in reputed engineering colleges and also 16 years of industrial experience and he is presently working as Asst. Prof (EE) Yashoda Technical Campus, Satara(MH) He has various publications in National \& International Journal/Conferences. 